\title{
Attitudes of Young Adults in Palestinian Universities About Seeking Psychological and Social Counselling from Professionals in Relation to a Set of Variables
}

\author{
Hreish Khalid ${ }^{1}$, Fareed Anan ${ }^{1}$, Okkeh Muhammad ${ }^{2}$, Hreish Nidal $^{3}$ \\ ${ }^{1}$ Department of Social Work, Al-Quds University, Abu Dis Campus, Jerusalem, Palestine \\ ${ }^{2}$ Department of Social Work, Palestine Ahliya University, Bethlehem, Palestine \\ ${ }^{3}$ Department of Special Education, David Yellin Academic College of Education, Jerusalem
}

Email address:

hreish1@yahoo.com (H. Khalid), ananfareed@hotmail.com(F. Anan), muhokkeh@paluniv.edu.ps (O. Muhammad), hreish_nidal@yahoo.com (H. Nidal)

\section{To cite this article:}

Hreish Khalid, Fareed Anan, Okkeh Muhammad, Hreish Nidal. Attitudes of Young Adults in Palestinian Universities About Seeking Psychological and Social Counselling from Professionals in Relation to a Set of Variables. Social Sciences.

Vol. 10, No. 5, 2021, pp. 241-250. doi: 10.11648/j.ss.20211005.16

Received: September 14, 2021; Accepted: October 21, 2021; Published: October 30, 2021

\begin{abstract}
This study aimed to identify the extent of Al-Quds University students' willingness to seek psychological and social assistance from professional specialists and tried to answer the following question: To what extent Al-Quds University students are ready to request psychological and social assistance and its relationship with the following variables: gender, school year, place of residence, religiosity, family economic status, and academic major? The researchers used the descriptive approach, and the questionnaire study tool of Haj Hamad in order to collect data from the field, achieve the goal of the study, and answer its questions. The total sample size was 951 students (male and female). The results of the study revealed that there were significant differences in the demographic variables. In particular, it was found that females were more inclined to seek psychological and social assistance than males did, and that fourth-year students were more willing to seek help than other academic years. Also, the findings showed that there were no difference in the students' responses according to the place of residence (cities, villages, camps), as the answers of the questions were close. Additionally, the results indicated that the very religious people were more likely to seek help from the conservatives, followed by the religious. Moreover, those with a higher economic status were more inclined to seek help than their counterparts of medium or low economic families. Furthermore, the findings revealed that there were no differences in the students' answer between the humanities and scientific disciplines.
\end{abstract}

Keywords: Psychological Counseling, Social Counseling, Al-Quds University Students, Palestinian Young Adults, Processional Specialists

\section{Introduction}

It is taken for granted that university life signifies a new and completely different life experience young adults usually pass through. It is an experience that is obsessed with much pressure and lots of conflicts and concerns, whether they be academic, social, psychological, or, sometimes, emotional. This is due to the fact that a young adult who has just finished high school education will move from a familiar social and educational environment he/she has been raised in and adjusted to since childhood into one that is completely different and, therefore, requires different adaptation strategies to qualify the students to coexist with and/or counter the extraordinary challenges being posed by university-life specifics. The situation even worsens when a student faces unusual types of problems and conflicts that expose him/her to unchallengeable psychological conflicts, which negatively impacts their abilities to adjust and to feel content within themselves and also to integrate within the family and interact with the larger community [16].

When the student fails to adapt to the new environment, his/her academic performances usually weaken. As such, the students suffering such troubles will find themselves in a bad need to seek intervention and counseling from the others to 
help them improve their well-being, alleviate distress and maladjustment, resolve crises, and increase their abilities to function better in their lives. However, many students are reluctant to seek this kind of psychological and social help from the others, which might be due to certain personal, psychological, and social pressing factors [13].

\section{Literature Review}

The theoretical literature on university life experience and the psychological and social pressures university students usually encounter pays particular attention to the needs by the students to seek solutions to such problems and conflicts from professional social specialists and experts. The bulk of studies reviewed by the researchers attempted to address the factors underlying the extent of willingness by the students to seek intervention and counseling, which are primarily personal, demographic, and family factors.

The previous studies that have been covered by this study reveal that university students who are exposed to academic, psychological, and social pressures while on campus or when interacting with the outside community are likely to develop inappropriate character traits and bad ways of conduct and achieve low-level academic performances. As a result, the individuals who encounter such experiences usually opt for various strategies to deal with this problematic situation. These strategies vary following the different options available for the individual, including the cultural, environmental, and demographic variables that negatively influence the individual's behavior and manner of interaction with the constituents of the social environment surrounding $\mathrm{him} /$ her. The individual will be badly affected if it happens that she/he joins a university located in a demographic environment that is far different from the one they live in, like when moving from a Bedouin area to an urban one, or from a refugee camp to a city, or from a city to a village or vice versa. Therefore, the way an individual acts and behaves will change following the nature of the life activities and social demands and norms of the new demographic environment [8].

Scientists who quest demographic phenomena were the first to try to define the concept of "Youth" (young adulthood) as an age segment (life span). We find that they have based their definitions of this age category on an external criterion, which is age in its physical sense, or on the span of life a young man passes when interacting with the community around him/her. However, specialists in this domain disagree amongst themselves when they come to determine the point of beginning and end of this life span of the individual. A group of them argue that an individual who is under twenty years of age is said to be a youth (young adult); accordingly, this group of scientists defines the end of the youth age, but not the beginning. Another group claims that Youth refers to those individuals who are aged between 15 and 25 years. The last group considers all persons who are between 15 and 30 to be young adults [7].

What's interesting about this is that "Youth", as a span of life, it is usually marked with psychological, physical and social transformations that are determined by temporal limits, and extend mostly from the age of 15 to the age of 30 [18].

As released by the Palestinian Central Bureau of Statistics youth (young adulthood) considered as an age segment in Palestine, i.e. Palestinians who fall in this age category, makes up the largest portion of population in the Palestinian society [24]. It was found that the total population in 2017 was $4,953,168$, and that $29.7 \%$ of them aged between 15 and 29, in both the West Bank and Gaza Strip.

Besides, university life constitutes a major stage in the life of Palestinian young adults, during which they are exposed to substantial unique challenges that prompt university students to either cope with by themselves or to seek support from professional and social specialists and experts.

\subsection{Relation Between University Youths and University Life in the Palestinian Society}

The university as an academic institution stands on the top of the educational system. This is due to the fact that universities play big roles in the social life of individuals and they are the institutions that are entitled to prepare individuals for the future through equipping with the necessary vocational skills to help their fellowmen and communities advance and prosper. Universities in this sense have tremendous scientific impacts on the nature and orientations to labor and production [5].

Among the objectives behind establishing universities is to better prepare the human resources for work in all fields of the life of the society. Therefore, the university leadership has to afford all stuff needed to care for the students, including the psychological, social, mental, physical, and economic needs [4].

\subsection{Challenges Facing University Youths Around the Globe}

As stated earlier, university life in all its academic, social, psychological and behavioral aspects constitutes a source of immense pressures that students usually find themselves under. This is because every stage in the life of the individual has its particular characteristic features and pressing experiences. Similarly, university students suffer from certain pressures, like test anxiety and interacting with peers and professors, as well as the challenges encountered when competing for success. They are also encountered with emotional conflicts, how to respond to the necessities of the university environment, how to deal with the laws and regulations being applied by the university system, beside other aspects of university life that sometimes limit their freedoms.

In a study carried out by [2], he defined a number of challenges university students usually face. These challenges relate to the individual's health and body needs, academic adaptation and achievement, time management, ethical codes and religion, interactions with the others, emotional relationships, marriage and gender needs, social contacts, as well as challenges relating to making living, employment, 
home and family integration, and relations with the parents and siblings.

\subsection{Problems Facing Palestinian University Youths in General}

The Palestinian context is, beyond any doubt, exceptional in terms of the multitude of the extraordinary aspects it stands out with. Palestinians, including young adults, are subjected to daily unendurable pressures and stresses that inflict every single aspect of their lives. These are manifest in the Israeli occupation's daily measures and atrocities that turn the lives of Palestinian youths into a real suffering. In this respect, we dare say that the pressures Palestinian universities' youths encounter are unmatched, even though the responses and behaviors might converge in one way or another [17]. According to [4], Palestinian university youths face problems relating to lack of space for recreation in the university premises and unsuitable university facilities and utilities, inappropriate educational system, and psychological, moral, gender, and social problems.

\subsection{Palestinian University Youth's Needs for Effective Services}

Young adulthood, as a stage in the life of the individual, marks transition from childhood to adulthood. It is usually accompanied with special psychological and emotional needs that are sometimes inflicted with suffering, frustration, or social pressures resulting from troubles in the family, the school or university, or the society. It is in fact a stage for sexual maturity and vocation choice. Therefore, this stage is the most critical one in the life of an individual, which requires adequate sound counseling, guidance, and support. When they find themselves incapable of facing the challenges being imposed on them, youths at this stage become in desperate need for intervention from another party to help them pass this stalement through professional counseling and guidance. The question that arises here revolves around whether such psychological and social services and counseling are accessible to a university student and how much he/she is ready to seek help from professional social specialists and workers on emotional, psychological, and social problems [25].

\subsection{University Student's Willingness to Seek Psychological and Social Counseling}

Taking the decision of seeking, or not, for help when the student finds him/herself under certain kind of pressures and conflicts might follow contradicting considerations. The individual needs to consolidate his/her personal interests and solve any problems they might face with the help of the others. However, an individual seeking any assistance might need to pay an amount of money in return for the help of the professional specialist. Some students think that seeking counseling is stigmatized and is on the expenses of his/her dignity and self-confidence, especially when they admit failure and inability to personally challenge difficulties and problematic situations. In the area of education studies, researchers investigated seeking help in different contexts. For example, school and university students seek help in order to overcome adaptation difficulties and to improve their academic performances [20].

\subsection{Factors Underlying Willingness to Seek Counseling}

Based on the theoretical literature, there are three categories of factors that might relate to the individual's willingness to seek psychological and social counseling from professionals [3]. These include the circumstantial, the personal, and the demographic factors.

Circumstantial factors relate to the problematic circumstances, conditions, or hardship posed on the individual. A study by [9] on the relationship between the intensity of the hardship and readiness to seek help, which was conducted on a sample of 997 adults to measure the amount of depression and anxiety they had, demonstrated that there was correlation between mental health and willingness to seek help. The results revealed that the students who had suffered more depression and stress were more ready to seek help than those who had fewer stresses and less depression.

Personal factors are represented in self-restrain, selfesteem, self-confidence and stigma. A study carried out by [11] on a sample of 524 university students showed that there was correlation between the personal traits and willingness to seek help among university students.

Studies also show that demographic factors impact the degree of the individual's readiness to seek counseling. Demographic factors in this sense relate to gender, year level at the university, the type of place of residence, the practice of religious duties, the living standard, and the field of specialization at the university $[22,28]$.

\subsubsection{Gender Differences}

The literature reviewed indicates that gender (sex) plays a major role in determining the individual's willingness to seek counseling [23]. It was found that seeking counseling could be predicted based on gender, and that women are more likely to seek help $[10,14]$.

The results of a study by [17], which was conducted on a sample of 515 students enrolled in Palestinian universities that offer social work programs, showed that there were no differences in willingness to seek psychological and social counseling that could be attributed to gender, which shows that are no correlations between inclination to seek counseling and the sex of the students. Another study by [8] on a sample of 484 education undergraduates at the University of Jordan revealed that there were no significant differences between males and females in terms of applying the strategies needed to challenge psychological pressures.

\subsubsection{Student's Year Level at the University}

Fleishman [15] carried out a study to investigate the attitudes of university students to seeking psychological counseling and to compare the students' orientations and the 
level of psychological symptoms against the demographic variables, the previous experience, seeking instructional assistance, and the level of social support. The study sample consisted of 256 third year male and female students who aged between 19 and 21 and who were students at three private universities in Pennsylvania. The results of the study demonstrated that there were no significant correlations between the subjects' orientations towards psychological counseling and the intensity of psychological symptoms and the available social support. It was discovered that the variables of gender, major, and the previous attitudes to seeking counseling were influential factors. Female students showed more positive attitudes to seeking counseling than did male students. Students who had received previous counseling were expressed more positive attitudes to receiving assistance and so did students in the program of Psychology.

Salhab [25] did a study on a sample of 506 female and male students at two universities in Gaza Strip. The results of the study indicated that there were no significant differences in the academic performances of students in all levels that could be attributed to the level of the year of study. However, the study by [8], which was carried out on a sample of 484 female and male Education students at the University of Jordan, showed that there were differences in the level of performance for the benefit of four-year students.

\subsubsection{Type of Place of Residence}

Place of residence is the geographical area where a group of people reside and practice their economic, cultural and social life activities on. Life in the city environment is usually modern and free, whereas that in the village is traditional and patriarchal in terms of community member's relations. Refugee camps, created in the aftermath of the Israeli occupation 1948, on the hand, are remarkably crowded quarters and residents there suffer incredible lifeconditions and are noticeably poor.

The results of a study by [16] on the barriers that hinder residents of rural areas from seeking psychological and social counseling and assistance showed that there are several obstacles relating to this, including barriers on the ground, stigma (disgrace), culture, social views, logistics, and selfdependence.

The results of a study by [17] on a sample of 515 male and female Palestinian students of Social Work showed that there were differences that could be attributed to the type of place of residence in terms of seeking assistance, and that willingness to seek help is linked to the type of residence area. It was found that city students had more positive attitudes to seeking counseling than did village, Bedouin, and refugee camp students.

\subsubsection{Commitment to the Teachings of Muslim Faith}

Commitment to the teachings and duties of Islamic Faith means that a Muslim practice the teachings of the Holy Quran and those ordained by Prophet Mohammad, which comprise the values, principles, ideals, and ethical codes of life preached by the Muslim Faith, as well as the worship of
God [12]. The religious practices, whether in public or secretly, are triggered by deep belief in God, which means that the Muslim commits him/herself to worship God and observe Islamic teachings pertaining to the Islamic code of morals and interactions with others so as to please God and live in harmony with the others [6]. Commitment to the teachings of Islam helps the believer live peacefully and protects him against psychological disorders and emotional conflicts. It a spiritual remedy that encounters such mental and social diseases and vices [1].

In a study carried out by [19] on a sample of Muslim individuals, who aged between 20 and 50, it was found that religion practitioners had higher levels of adaptation and acceptance by the others. A Muslim who does the prayer on a regular basis and with humiliation is consequently selfcontent and feels calm and tranquility simply because he believes that God will help him and relive his sufferings. Therefore, this category of Muslims usually turns to God for assistance rather than to professional specialists and social workers compared to non-religion practitioners.

However, the study done by [17] on a sample of 515 female and male students who studied Social Work at Palestinian Universities found that there are differences in attitudes about seeking counseling that could be attributed commitment to Muslim Faith. Less committed students are more ready than committed students to seek counseling.

\subsubsection{Standard of Living}

Literature demonstrates that there is correlation between the socio-economic level of the individual and the attitude about seeking assistance [21]. A study by [27] on a sample of young adults to measure the relation between the socioeconomic standard and readiness to seek counseling found that students of low economic levels and social statuses and backward communities were less ready to seek assistance than those who lived under better conditions. This result reinforces those reached by [26], which indicated that the more a person moves up the social and economic scale the more he/she becomes ready to seek assistance. Another study by [17] on a sample of 515 male and female students who studied social work at Palestinian universities showed that there were differences.

\subsubsection{Student's Area of Study}

Salhab [25] did a study on a sample of 506 universities in Gaza Strip which demonstrated that there were differences in attitudes of the subjects of the study that could be attributed to area of study, humanities vs. science. Students of humanities showed more positive attitudes.

Fleishman [15] did a study on 256 male and students who aged between 19 and 21 at three Pennsylvania-based universities. It was found that Psychology students tended more than other students to ask for help.

\section{Research Question}

The present study attempted to answer the following research question: 
What are the attitudes of Al-Quds University students about seeking psychological and social counseling from professional specialists in relation to the variables gender, level of year of study, type of place of residence, commitment to religion duties, standard of living, and area of study (humanities vs. science programs)?

This research questions shows that there is an immediate need to determine the quantity of differences when measuring any significant differences in the aforementioned independent variable in the Table 1.

Table 1. Distribution of members of the sample over the variable of the study.

\begin{tabular}{llll}
\hline Variable & Level & Number & Percentage \\
\hline Gender & Males & 404 & 42.5 \\
& Females & 547 & 57.5 \\
Level of year of study & First Year & 212 & 22.3 \\
& Second Year & 276 & 29.0 \\
& Third year & 274 & 28.8 \\
& Fourth Year and Above & 189 & 19.9 \\
& City & 341 & 35.9 \\
Type of Residence Area & Village & 345 & 63.3 \\
& Refugee Camp & 265 & 27.9 \\
Commitment to Religion & not committed & 113 & 11.9 \\
& Conservative & 529 & 55.6 \\
& Moderately committed & 240 & 25.2 \\
Standard of Living & Much committed & 69 & 07.3 \\
& Low & 146 & 15.4 \\
Area of Study & Average & 635 & 66.8 \\
& High & 170 & 17.9 \\
\hline
\end{tabular}

Table 1, above shows the percentages calculated for the distributions of the members of the sample. In details, it shows the percentage for the variable of gender is $42.5 \%$ for males and $57.5 \%$ for females; for variable of level of year of study $22.3 \%$ for first-year students, $29 \%$ for second-year students, $28.8 \%$ for third-year students, and $1909 \%$ for fourth-year students and beyond; for the variable of type of place of residence $35.9 \%$ for city/town, $36.3 \%$ for village, and $27.9 \%$ for refugee camp; for commitment to religion duties $11.9 \%$ for non-committed students, $55.6 \%$ for conservative students, $25.2 \%$ for committed students, and $7.3 \%$ for much committed students; for the variable of standard of living $15.4 \%$ for low level standard of living, $66.8 \%$ for average standard of living, and $17.9 \%$ for high standard of living; for the variable of area of study $51.2 \%$ for humanities subjects and $48.8 \%$ for science subjects.

\section{Method}

The study was reviewed by the research ethical committee of Al-Quds University, and data was collected in the period between September and December 2017 by applying Haj Hamad's questionnaire [17]. This questionnaire offers a good framework that is capable for comparing data because it had been developed and tested in a number of Palestinian universities.

The sample of the study consisted of 951 students (404 males and 547 females) who were selected from the total community of 9035 Bachelor male and female students of Al-Quds University enrolled in various major programs in the first semester of the academic year 2017-2018. (Note: Table 1 shows the distribution of the study sample).

To achieve the objectives of the study, the researchers applied the method of descriptive analysis which is defined as the method that traces a current event or issue with data answering questions of the research without any interference by the researchers performing the study. In this approach, researchers attempt to describe the phenomenon that makes up the subject, analyze its data, and show the reactions between its constituents and opinions pertaining to the way they operate and the impacts they might have on other things or phenomena. This method is one of the methods of analysis and interpretation that are applied to describe a phenomenon or problem, to sort it out and further study and analyze it.

\subsection{Instrument of the Study}

The instrument applied by present study was designed by [17]. This instrument consists of two parts:

The first part deals with the independent variables of gender, academic level, place of residence, degree of devotion to religion, economic level of student's family and field of study.

The second part consists of a table of 20 items that measure the degree of readiness on the part of the student to seek psychological and social assistance. The students involved in the study were offered 5 choices to choose from based on Likert Scale, which is used to represent people's attitudes, and which has the following format:

Strongly agree, Agree, Neutral, Disagree, strongly disagree

Validity and Reliability of the Instrument:

Haj Hamad [17] reviewed the validity and efficiency of the terms applied by the questionnaire through calculating the total grade of the validity of the coefficient for the study domains based on Cronbach's alpha. The total degree of the attitudes of AQU students about seeking psychological and 
social counseling was 0.807 , which demonstrates that this instrument was valid for the study.

\subsection{Statistical Procedures}

After collecting the questionnaire and testing its validity, it was given certain codes (certain numbers in order to be able to upload them using a computer program and then to process and analyze them based on study questions. The data was processed by calculating the means and standard deviations for each item of the questionnaire and through applying ttest, One Way ANOVA, Pearson correlation coefficient, Cronbach's alpha, and through using Statistical Package for Social Sciences SPSS).

\section{Findings}

The research question is "What are the attitudes of AlQuds University students about seeking psychological and social counseling for professional specialists?"

This research question was responded to based on calculating the means and the standard deviations of the study sample's responses on the questionnaire items that express the attitudes of Al-Quds university students about seeking psychological and social counseling. The mean calculated for the total degree was 3.16, and the standard deviation was 0.537 . These figures indicate that the levels of attitudes of Al-Quds University about seeking psychological and social assistance were around the average.

Also, the results show that most of items were of average degree and that 3 items were of high degree. The item of "I feel stigmatized when I reveal my personal troubles to my friends" received the highest means, which is 3.91 followed by the item of "I feel afraid of unveiling my personal troubles to my friend because they are considered a secret", with a mean of 3.89; then comes the item of "I see it is shame to ask official institutions for financial aid", which received a mean of 2.83. The item of: "I prefer to keep suffering from psychological conflicts and troubles than seeking assistance from specialists", received the least mean, 2.63".

\subsection{Results Pertaining to the Second Question}

Do the attitudes of Al-Quds University students about seeking psychological counseling differ following the variables of gender, level of year of study, type of place of residence, commitment to religion duties, standard of living of the family, and area of study (specialization)?

To answer this question, the researcher transferred it into the following hypotheses.

\subsection{Results on the First Hypothesis}

There are significant differences at $0.05 \geq q$ in terms of attitudes of Al-Quds University students about seeking counseling that can be attributed to the variables of gender, which is for the benefit of female students.

The first hypothesis was tested through calculating the results of t-test and the means on the study subjects' attitudes about seeking counseling pertaining to the variable of gender.

Table 2. Results of t-test for the independent sample's responses pertaining to the variable of gender.

\begin{tabular}{llllll}
\hline Gender & Frequency & mean & standard deviation & standard error & t value \\
\hline Males & 404 & 0.55519 & 3.0923 & 0.02762 & 3.804 \\
Females & 547 & 0.51777 & 3.2256 & 0.02214 & 0.000 \\
\hline
\end{tabular}

It is clear from the above table that the $\mathrm{t}$ vale for the total grade is 3.804 , and the degree significance calculated is 0.000 , which means that there were no significant differences in the attitudes of the students that could be attributed to gender, and the differences were for the benefit of females. As such, this hypothesis was accepted.

\subsection{Results on the Second Hypothesis}

There are significant differences at $0.05 \geq \mathrm{q}$ in the attitudes of Al-Quds University students about seeking counseling that could be attributed to the variable of level of year of study. It was found that fourth-year students had positive attitudes.

The second hypothesis was tested and the means of the responses of the subjects regarding the attitudes about seeking counseling pertaining to the variable of the level of the year of study were calculated. One Way ANOVA was applied.

Table 3. Results from One Way ANOVA on the responses pertaining to the attitudes of the subjects to seeking psychological and social counseling that could be attributed to the variable of level of year of study.

\begin{tabular}{lllllll}
\hline Academic year & Frequency & Mean & Standard deviation & Standard error & f value & p value \\
\hline First year & 212 & 3.1144 & 0.56446 & 0.03877 & 3.697 & 0.0012 \\
Second year & 276 & 3.1583 & 0.2816 & 0.3179 & 3.697 & 0.012 \\
Third year & 274 & 3.1449 & 0.51738 & 0.03917 & & \\
Fourth year and beyond & 189 & 3.2807 & 0.53855 & 0.03917 & \\
\hline
\end{tabular}

The table above shows that $\mathrm{f}$ value for the total grade is 3.697 and the degree of significance is 0.012 which is below $0.05 \geq \mathrm{q}$. This indicates that there are significant differences in the attitudes of the subjects about seeking counseling that can be attributed to the variable of level of year of study. The differences were for the benefit of fourth-year students. Therefore the hypothesis was accepted. 


\subsection{Results on the Third Hypothesis}

There are significant differences at $0.05 \geq \mathrm{q}$ in the attitudes of the subjects about seeking counseling that could be attributed to the variable of the type of residence, based on applying One Way ANOVA.

Table 4. Results of One Way ANOVA for the attitudes of the subjects to seeking counseling that could be attributed to variable of type of residence.

\begin{tabular}{lllllll}
\hline Type of place of residence & Frequency & Mean & Standard deviation & Standard error & f value & p value \\
\hline Town & 341 & 3.1710 & 0.55875 & 0.03026 & 1.508 & 0.222 \\
Village & 345 & 3.1348 & 0.51738 & 0.02787 & 1.508 & 0.222 \\
Refugee camp & 265 & 3.2109 & 0.53521 & 0.03288 & & \\
\hline
\end{tabular}

The data shows that $\mathrm{f}$ value for the total grade is 1.508 and the degree of significance is 0.222 which exceeds $0.05 \geq \mathrm{q}$. This gives that there are no significant differences in the attitudes of the subjects about seeking counseling that could be attributed to the variable of the type of place of residence. Therefore, this hypothesis was accepted.

\subsection{Results on the Fourth Hypothesis}

There are significant differences at $0.05 \geq q$ in terms of the attitudes of the subjects to seeking counseling that could be attributed to the variable of commitment to religion duties. This shows that the students who do not practice religion duties have more positive attitudes about seeking counseling than do moderate or extreme religion practitioners.

The researcher tested the fourth hypothesis and calculated the means of the responses of the subjects pertaining to the degree of readiness to seek counseling that could be attributed to the variable of commitment to religion. He also used One Way ANOVA for this purpose.

Table 5. Result of One Way ANOVA for the responses of the subjects regarding the attitudes about seeking counseling that could be attributed to commitment to religion.

\begin{tabular}{llllll}
\hline Commitment to religion duties & frequency & means & standard deviation & standard error & f value \\
\hline Non-religious & 113 & 3.0274 & 0.55267 & 0.05199 & 3.005 \\
Conservative & 529 & 3.1895 & 0.52526 & 0.02284 \\
Religious & 240 & & 3.1815 & 0.54349 \\
Very religious & 69 & 3.2000 & 0.56432 & 0.06794 \\
\hline
\end{tabular}

The table shows that $\mathrm{f}$ value for the subjects' response on the degree of commitment to religion duties is 3.005 with a significant degree of 0.030 , which is below $0.05 \geq \mathrm{q}$. This indicates that there are no significant differences in the attitudes of Al-Quds University students about seeking psychological and social counseling that could be attributed to the variable of commitment to religion. Accordingly, the fourth hypothesis was rejected.

\subsection{Results on the Fifth Hypothesis}

There are significant differences at $0.05 \geq \mathrm{q}$ in the attitudes of the students about seeking psychological and social assistance that could be attributed to the variable of standard of living. It was found that the attitudes of students with high standards of living are more positive.

Table 6. Results of One Way ANOVA for the responses pertaining to the attitudes of Al-Quds University students to seeking psychological and social counseling that could be attributed to standard of living.

\begin{tabular}{llllll}
\hline Standard of living & Frequency & Mean & Standard deviation & Standard error & f value \\
\hline Low & 146 & 3.0545 & 0.53537 & 0.04431 & 3.949 \\
Average & 635 & 3.1882 & 0.53012 & 0.02104 \\
High & 170 & 3.1956 & 0.55855 & 0.04284 \\
\hline
\end{tabular}

The fifth hypothesis was tested and the means of the subjects' responses that could be attributed the variable of standard of living were calculated. One Way ANOVA was also applied.

It can be noticed that $f$ value for the total grade is 3.949 and the degree of significance is 0.020 which is below $0.05 \geq \mathrm{q}$. This indicates that there are no significant differences in the attitudes of Al-Quds University students about seeking counseling that could be attributed to the variable of standard of living. Therefore, the hypothesis was accepted.

\subsection{Results on the Sixth Hypothesis}

There are significant differences at $0.05 \geq \mathrm{q}$ in the attitudes of AQU students about seeking counseling that could be attributed to the variable of area of study. The attitudes of the students in the humanities programs are more positive compared to those of science students'.

This hypothesis was tested through calculating the results of applying t-test and the means of the subjects' responses pertaining to the variable of area of study. 
Table 7. Results of applying t-test on the responses of the members of the independent samples pertaining to the attitudes about seeking counseling that could be attributed to the variable of area of study.

\begin{tabular}{llllll}
\hline Specialization & frequency & mean & standard deviation & standard error & t value \\
\hline Humanities majors & 487 & 3.1632 & 0.55586 & 0.02519 & 0.337 \\
Science majors & 464 & 3.1750 & 0.51862 & 0.02408 & 0.736 \\
\hline
\end{tabular}

Table 7, shows that $t$ value for the total grade is 0.337 and the degree of significance is 0.736 which is higher than 0.05 $\geq \mathrm{q}$. This indicates that there are no significant differences in the attitudes of AQU students about seeking counseling that could be attributed to the area of study. Therefore the sixth hypothesis was rejected.

\section{Discussion}

The present study was carried out to measure the attitudes of Al-Quds University students to seeking psychological and social counseling from professional specialists. The researchers collected the subjects' responses to the research question, and it was found that means for the total grade was 3.16 and the standard deviation was 0.537 . This indicates that the attitudes of the community of the study were around average, and 3 items received higher mean. The item of "I feel that it is stigmatized to tell friends about the personal troubles I have" received 3.91, which is the highest mean, and the item of "I prefer to remain suffering psychological troubles and conflicts than turning to professional specialists for counseling on my troubles" received the lowest mean, which is 2.63 .

The results of the study show that female students seek counseling more than do male students. This result corresponds to the results of the study [11], whereas it contradicts the results of the study by [17] which indicates that there are gender differences. The results of the study also demonstrates that there are differences in the attitudes to seeking counseling that could be attributed to the level of year of study, where fourth year students are more ready to seek counseling than do students in lower levels. This result correlates with the results of the study by [8] but not with Salah's study [25] which showed that there are no differences.

The results show that there are no differences in the attitudes of the students that could be attributed to the type of place of residence. This result contradicts the one [17] reached, which found that there were differences that could attributed to the type of place of residence for the benefit of city residents. As for the degree of commitment to religion duties it was found that the students who practice religion duties seek counseling more than those who are not committed to religion duties, a result that does not match the results of the studies of [19] nor the results of the study of [17]. Regarding the standard of living of the student, it was found that students to have higher standards of living resort to professional specialists for counseling more than do low standard of living students, a result similar to the results reached by $[27,26,17]$. Finally, there are no significant differences in the attitudes about seeking counseling that could be attributed to the area of study of the students, humanities vs. science programs. This result is different from the results Salah's study [25] which found that there were significant differences pertaining to humanities.

\section{Conclusion}

The study examined the extent to which Al-Quds University students are willing to seek psychological and social assistance from professional specialists and how this relates to a number of variables. In order to achieve the objectives of the study and to answer its questions, the researchers applied a questionnaire to the study sample, and the findings of the quantitative study were carefully analyzed and interpreted in light of the statistical hypotheses previously proposed. Statistical analysis of the data was used to extract the arithmetic means and standard deviations for each item in the questionnaire. The t-test, one-way ANOVA, Pearson correlation coefficient, and Cronbach Alpha stability equation were also conducted using statistical packages (SPSS). The results were then linked to previous theories and studies adopted by researchers. Due to the peculiarity of the Palestinian society and its unique life constraints, the local university student differs from his/her peers elsewhere in the world, as he/she may bear some pressure as if it was just a routine matter. Thus, this study may be distinguished from previous surveys due to the difference in the standard population and the nature of the sample to which the study tool was applied. It was noted that the findings of this study differ from other studies based on the independent study variables. The study literature addressed the Palestinian universities, and the problems confronting young people in general and Palestinian in particular during their university studies. Also, we discussed how students could seek social and psychological help and the most important factors that make a student ready to request assistance. Additionally, study variables were addressed, and we also touched upon how the study attempted to measure both differences and intersectional relationships between relevant variables.

\section{Funding}

No financial support for conducting this study or for authorship or publication was received from any persons or institutions whatsoever. 


\section{Appendix}

Dear Student:

This questionnaire is part of a study designed to measure the attitudes of Al-Quds University students about seeking psychological and social counseling from professional specialists in relation to a set of variables. The data and answers you are going to provide us with are meant for scientific research only and will remain confidential. You cooperation is highly appreciated as the study is intended for publication in international refereed journals.

Regards!

Section One: Primary Information

Sex:

a. Male

b. Female

Level of year of study:
a. First Year
b. Second Year
c. Third Year
d. Fourth Year and Above

\section{No. Item Agree Strongly (5) Agree (4)}

1. I am ready to seek psychological counseling from a professional specialist.

2. I am ready to seek help to solve the troubles I face.

3. I am ready to reveal the personal troubles I have to others.

4. I do not mind seeking psychological counselling from a professional specialist.

5. I do not mind telling a professional specialist about the troubles I have.

6. I do not see it a shame to reveal the emotional troubles I have to professional specialists.

7. I am ready to ask others for help to accomplish the requirements of my university studies.

8. I do not see it is stigmatized to turn to official institutions for financial aid.

9. I advise colleagues to seek for psychological and social and vocational counseling.

10. I encourage colleagues to seek social and vocational counseling.

11. I believe in and trust positive role of the psychological support of others.

12. I do not feel it is stigmatized to turn to advisors at the office of students' affairs for a help.

13. I prefer to endure psychological conflicts and troubles than turning to a specialist for a help.

14. I do not feel it is shame to ask parents to help me settle the troubles I have.

15. I candidly tell family about the fears the inflict me
Type of Place of Resident:
a. City/Town
b. Village
c. Refugee Camp

Commitment to Religion Duties:
a. Not committed
b. Conservative
c. committed
d. highly committed

Standard of Living:
a. Low
b. Average
c. High

Area of Study:

a. Humanities

b. Science

Attitudes of Al-Quds University about Seeking Psychological and Social Counseling from Professional Specialists in Relation to a Set of Variables:

Section Two: Kindly tick $(\sqrt{ })$ the choice you think best expresses your viewpoint as to the item provided.

Neutral (3) Do not agree (2) Do not agree strongly (1)

when preparing for exams.

16. I feel relaxed after I tell parents about things that annoy me.

17. I do not mind telling family about the sensitive troubles I have.

18. I feel it is stigmatized to share friends with the secrets of my own concerns.

19. I fear telling friends about the troubles I have for they are personal matters.

20. I do not mind taking advice from family to overcome the troubles I have.

\section{References}

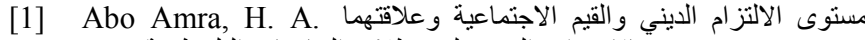
The Level of the Religious Commitment and The Social Values and their Relationship to the Psychological Alienation of Palestinian Students at Gaza Universities], A Thesis Submitted as a partial Fulfillment of the Requirements for the Master Degree in Psychology, Education Faculty, AL - Azhar University - Gaza lestine. 2013.

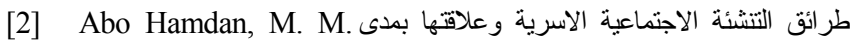

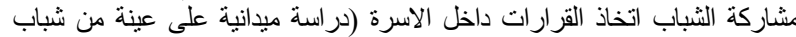
(Household and Social Upbringing and its Relation in Youth participation in Decision Making within the Family], Damascus University Journal. 2011, 27, (3+4), 363-399.

[3] Alaealdin, M. J. اتجاهات الطلبة الجامعيين نحو السعي للمساعدة College Students' Attitudes Toward Seeking Psychological Help: The Role of Personality Factors], Dirasat: Educational Sciences. 2011, $38,(4), 1525-1485$. 
[4] Al bana, A. H. \& Alrabi, A. A. مشكلات طلبة جامعة الأقصى بغزة من ]Al-Aqsa university student's problems in Gaza from the point of view of the students], Islamic University for Humanitarian Research Journal. 2006, 14, (2), 505-537.

[5] Al Ghamdi, A. B. المشكلات التي تو اجه طالبات البرامج الانتقالية في كلية Problems Facing Students of Transitional Programs in the Faculty of Applied Studies and Community Service, King Saud University], International Journal of Educational \& Psychological Studies (EPS). 2018, 4, (3), 416-444.

[6] Al-Hajjar, I. B, \& Abo Ashaq, S. A. التو افق لاى مريضات سرطان الثدي بمحافظات غزة وعلافته بمستوى الالتزام الديني ومتغيرات أخرى، [Consensus among breast cancer patients in Gaza Governorates and its relation to the level of their religious commitment and other variables], Islamic University for Humanitarian Research Journal. 2007, 15, (1), 561-592.

[7] Alsuruji, T. M \& Abu Almatti, A. M. ميادين ممارسة الخدمة [Fields for practicing social services], Jordan, AlQuds Open University, national library, Jordan. 2016.

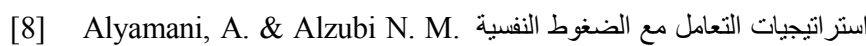
لدى عينة من طلبة البكالوريوس في كليات التربية في الجامعات الاردنية الرسمية، [Strategies to deal with the psychological stress studied over a sample of student's bachelor in the faculty of Education at the Jordanian Universities], Journal of Al-Quds Open University for Research and Studies. 2013, 1, (2), 213-246.

[9] Armando M, Nelson B, Yung AR, Saba R, Monducci E, Dario C, Righetti V, Birchwood M, Fiori Nastro P, Girardi P. Psychotic experience subtypes, poor mental health status and helpseeking behavior in a community sample of young adults. Early intervention in psychiatry. 2012 Aug; 6 (3): 300-8.

[10] Ashton, W. A., \& Fuehrer, A. Effects of gender and gender role identification of participant and type of social support resource on support seeking. Sex Roles. 1993, 28, (7+8), 461476.

[11] Atik G, Yalçin Y. Help-seeking attitudes of university students: the role of personality traits and demographic factors. South African Journal of Psychology. 2011 Sep; 41 (3): 328-38.

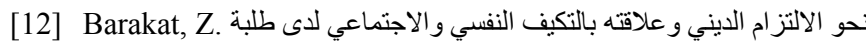
Religious Commitment Effected On Psychological and Sociological Adjustment and Related With Some Variables], Hebron University Research Journal. 2006, 2, (2), 110-139.

[13] Barksdale, C. L., \& Molock, S. D. Perceived Norms and Mental Health Help Seeking among African American College Students. The Journal of Behavioral Health Services \& Research. 2009, 36 (3), 285-299.

[14] Boldero, J., \& Fallon, B. Adolescent help-seeking: What do they get help for and from Whom? Journal of Adolescence. 1995, 18, (2), 193- 209.

[15] Fleishman-Pogach, L. College students attitudes toward seeking professional psychological help. Doctoral Dissertation, Chestnut Hill College, United States, Pennsylvania. Retrieved July 8, 2009, from Dissertations \& Theses: Full Text. (Publication No. AAT 3354297. 2008.

[16] Francis, K., Boyd, C., Aisbett, D., Newnham, K., \& Newnham, K. Rural adolescents' attitudes to seeking help for mental health problems. Youth Studies Australia. 2006, 25 (4), 42-49.

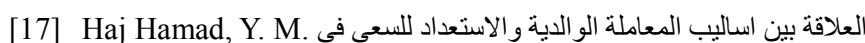

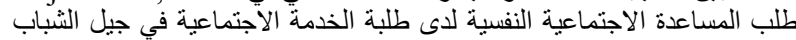
The Relation between Parental Treatment Methods and the Readiness to Seek Psycho-Socio Help Among Young Social Service Students in the Universities of the West Bank], A Thesis Submitted as aPartial Fulfillment of the Requirements For the Master Degree in Social Work, Al-Quds University - Abu Dis campus, Palestine. 2017.

[18] Hijazi, a. الشباب العربي ومشكلاته (سلسلة كتب ثقافية شهرية بصدرها Arab youth and their problems (a series of cultural books published monthly by the national council for culture and art], knowledge world, Kuwait. Hossain, M. S \& Siddique, M. Z. (2008). Does Religiosity Help Muslims Adjust To Death? A Research Note. Omega: Journal of Death \& Dying. 1985, 57 (1) 113-119.

[19] Hossain, M. S \& Siddique, M. Z. Does Religiosity Help Muslims Adjust To Death? A Research Note. "Omega: Journal of Death \& Dying" 2008, 57 (1) 113-119.

[20] Karabenick, S. A. Perceived achievement goal structure and college student help seeking. Journal of educational psychology. 2004, 96 (3), 569-581.

[21] Leaf, P. J., Bruce, M. L., Tischler, G. L., \& Holzer, C. E. The relationship between demographic factors and attitudes toward mental health services. Journal of Community Psychology. 1987, 15, (2), 275- 284.

[22] Lee J, Friesen BJ, Walker JS, Colman D, Donlan WE. Youth's help-seeking intentions for ADHD and depression: Findings from a national survey. Journal of Child and Family Studies. 2014 Jan 1; 23 (1): 144-56.

[23] Levant RF, Wimer DJ, Williams CM, Smalley KB, Noronha D. The relationships between masculinity variables, health risk behaviors and attitudes toward seeking psychological help. International Journal of Men's Health. 2009 Apr 1; 8 (1): 3.

[24] Palestinian Central Bureau of Statistics, (2017). تعداد، 2017- نسبة [Census 2017, - Percentage of Youth (15-29) years], Ramallah, Palestine. http://www.pcbs.gov.ps/site/lang_en/881/default.aspx?lang=en

[25] Salhab, S. A. إدر الك طلبة الجامعات الفلسطينية لدور المرشد النفسي وعلاقتهات Perception of Palestinian universities students toward psychological counselor role and its relation with some variables], Thesis Submitted to faulty of Education in the Islamic university for the Master Degree in Psychology, Gaza, Palestine. 2007.

[26] Saunders, S. M., Resnick, M. D., Hoberman, H. M., \& Blum, R. W. Formal seeking behavior of adolescents identifying themselves as having mental health problems. Journal of Child and Adolescent Psychiatry. 1994, 33, (5), 718-728.

[27] Surgenor LJ. Attitudes toward seeking professional psychological help. New Zealand Journal of Psychology. 1985 Jan 1; 14 (1): 27-33.

[28] Yap MB, Wright A, Jorm AF. The influence of stigma on young people's help-seeking intentions and beliefs about the helpfulness of various sources of help. Social Psychiatry and Psychiatric Epidemiology. 2011 Dec; 46 (12): 1257-65. 